\title{
Implications of lowering threshold of plasma troponin concentration in diagnosis of myocardial infarction: cohort study
}

\author{
(c) $\underset{\text { (1) () }}{\mathrm{gy}}$ OPEN ACCESS
}

\begin{abstract}
Nicholas L Mills BHF intermediate clinical research fellow ${ }^{1}$, Kuan Ken Lee medical student ${ }^{1}$, David A McAllister clinical lecturer in public health ${ }^{2}$, Antonia M D Churchhouse foundation year doctor ${ }^{1}$, Margaret MacLeod specialist nurse in cardiology ${ }^{3}$, Mary Stoddart advanced biomedical scientist ${ }^{4}$, Simon Walker consultant in clinical biochemistry ${ }^{4}$, Martin A Denvir consultant cardiologist ${ }^{1}$, Keith A A Fox professor of cardiology ${ }^{1}$, David E Newby professor of cardiology ${ }^{1}$
\end{abstract}

${ }^{1}$ BHF/University Centre for Cardiovascular Science, Edinburgh University, Edinburgh EH16 4SU, UK; ${ }^{2}$ Public Health Sciences, Edinburgh University, Edinburgh EH8 9AG; ${ }^{3}$ Edinburgh Heart Centre, Royal Infirmary of Edinburgh, Edinburgh EH16 4SA; ${ }^{4}$ Department of Clinical Biochemistry, Royal Infirmary of Edinburgh, Edinburgh EH16 4SA

\begin{abstract}
Objective To assess the relation between troponin concentration, assay precision, and clinical outcomes in patients with suspected acute coronary syndrome.

Design Cohort study.

Setting Tertiary centre in Scotland.

Participants 2092 consecutive patients admitted with suspected acute coronary syndrome were stratified with a sensitive troponin I assay into three groups $(<0.012,0.012-0.049$, and $\geq 0.050 \mu \mathrm{g} / \mathrm{L})$ based on the 99th centile for troponin concentration $(0.012 \mu \mathrm{g} / \mathrm{L}$; coefficient of variation $20.8 \%)$ and the diagnostic threshold $(0.050 \mu \mathrm{g} / \mathrm{L} ; 7.2 \%)$.
\end{abstract}

Main outcome measure One year survival without events (recurrent myocardial infarction, death) in patients grouped by troponin concentration.

Results Troponin I concentrations were $<0.012 \mu \mathrm{g} / \mathrm{L}$ in 988 patients (47\%), 0.012-0.049 $\mu \mathrm{g} / \mathrm{L}$ in 352 patients (17\%), and $\geq 0.050 \mu \mathrm{g} / \mathrm{L}$ in 752 patients $(36 \%)$. Adoption of the 99 th centile would increase the number of people receiving a diagnosis of myocardial infarction from 752 to 1104 : a relative increase of $47 \%$. At one year, patients with troponin concentrations of $0.012-0.049 \mu \mathrm{g} / \mathrm{L}$ were more likely to be dead or readmitted with recurrent myocardial infarction than those with troponin concentrations $<0.012 \mu \mathrm{g} / \mathrm{L}(13 \% \vee 3 \%, \mathrm{P}<0.001$; odds ratio $4.7,95 \%$ confidence interval 2.9 to 7.9 ). Compared with troponin $\geq 0.050 \mu \mathrm{g} / \mathrm{L}$, patients with troponin $0.012-0.049 \mu \mathrm{g} / \mathrm{L}$ had a higher risk profile but were less likely to have a diagnosis of, or be investigated and treated for, acute coronary syndrome.

Conclusion Lowering the diagnostic threshold to the 99th centile and accepting greater assay imprecision would identify more patients with acute coronary syndrome at risk of recurrent myocardial infarction and death but would increase the diagnosis of myocardial infarction by $47 \%$. It remains to be established whether reclassification of these patients and treatment for myocardial infarction would improve outcome.

\section{Introduction}

The consensus statement on the universal definition of myocardial infarction recommends that an increase in plasma troponin concentration above the 99th centile of a normal reference population is used to confirm the diagnosis. ${ }^{1}$ Despite this guidance, lowering the diagnostic threshold for troponin remains a highly contentious issue, with clinicians uncertain as to whether the benefits of improved sensitivity will outweigh problems that might arise from reduced specificity. ${ }^{2}$

The Global Task Force for the Universal Definition of Myocardial Infarction ${ }^{1}$ and the National Academy of Clinical Biochemistry ${ }^{3}$ recommend the 99th centile as the diagnostic threshold where assay precision can be shown with a coefficient of variation of $\leq 10 \%$ at this concentration. Currently few assays are able to meet these precision criteria at the diagnostic threshold and nearly all institutions therefore select a diagnostic threshold above the 99th centile where the coefficient of 
variation is $\leq 10 \%$ to minimise the risk of false positive results and an inappropriate diagnosis of myocardial infarction. We recently showed that the introduction of a sensitive troponin I assay halved the rate of recurrent myocardial infarction and death in patients presenting with suspected acute coronary syndrome and a small increase in plasma troponin

concentration. ${ }^{4}$ Despite improved sensitivity, this assay did not have the recommended level of precision at the 99th centile of $0.012 \mu \mathrm{g} / \mathrm{L}$. We therefore reduced the threshold from $0.200 \mu \mathrm{g} / \mathrm{L}$ to $0.050 \mu \mathrm{g} / \mathrm{L}$, the lowest concentration at which the coefficient of variation was $\leq 10 \%$, for the clinical diagnosis of myocardial infarction.

A recent statement from the Biochemistry Group of the Global Task Force for the Universal Definition of Myocardial Infarction represents a change in position, with the recommendation that the 99th centile be adopted as the diagnostic threshold for current sensitive troponin assays irrespective of whether the coefficient of variation is less than $10 \%$ at this concentration. ${ }^{5}$ This recommendation is based in part on modelling exercises that suggest assays with imprecision of up to $20 \%$ do not affect diagnostic accuracy. ${ }^{6}$ To determine the potential impact of this change in guidance on clinical practice, we evaluated the relation between plasma troponin concentration, assay precision, and clinical outcomes in our previous cohort of consecutive patients admitted to hospital with suspected acute coronary syndrome. ${ }^{4}$

\section{Methods}

\section{Study population}

We identified consecutive patients admitted with suspected acute coronary syndrome to the Royal Infirmary, Edinburgh, United Kingdom, during the validation (from 1 February 2008 to 31 July 2008) and implementation (from 1 February 2009 to 31 July 2009) of a sensitive troponin I assay. ${ }^{4}$

Inclusion criteria were symptoms of chest pain of suspected cardiac origin and measurement of plasma troponin I concentrations on admission or 12 hours after the onset of symptoms, or both. Exclusion criteria were non-cardiac (respiratory, gastrointestinal, or musculoskeletal) chest pain, tachyarrhythmia, anaemia (haemoglobin concentration $<900$ $\mathrm{g} / \mathrm{L}$ ), severe valvular heart disease, hypertrophic cardiomyopathy, pericarditis, cocaine use, or patients who were non-resident.

Information on patients and clinical outcomes were obtained through the TrakCare software application (InterSystems Corporation, Cambridge, MA, US), an electronic patient record system used by the Acute Hospitals Division of Lothian National Health Service Health Board, Scotland.

\section{Troponin assay}

Plasma troponin I concentrations were measured with the Abbott ARCHITECT troponin I assay (Abbott Laboratories, Abbott Park, IL, US). This assay was reformulated by the manufacturer to achieve a greater analytical sensitivity of $\leq 0.01 \mu \mathrm{g} / \mathrm{L}$ where the 99 centile of a reference population (men and women) was reported to be $0.012 \mu \mathrm{g} / \mathrm{L}$. We previously determined the interassay coefficient of variation across a wide range of plasma troponin concentrations and established that the reformulated assay showed a coefficient of variation of $<10 \%$ at $0.050 \mu \mathrm{g} / \mathrm{L}$ under local laboratory conditions. ${ }^{4}$ As recommended in the consensus statement on the universal definition of myocardial infarction, this was selected as the diagnostic threshold for clinical use. Patients were stratified into three groups based on the 99th centile for plasma troponin $(0.012 \mu \mathrm{g} / \mathrm{L})$ and the diagnostic threshold of $0.050 \mu \mathrm{g} / \mathrm{L}:<0.012 \mu \mathrm{g} / \mathrm{L}, 0.012-0.049$ $\mu \mathrm{g} / \mathrm{L}$, and $\geq 0.050 \mu \mathrm{g} / \mathrm{L}$.

A further evaluation of assay precision at low concentrations of troponin $(<0.050 \mu \mathrm{g} / \mathrm{L})$ was carried out by using donor plasma with undetectable troponin I (base pool) spiked with control material to achieve concentrations between $0.010 \mu \mathrm{g} / \mathrm{L}$ and $0.050 \mu \mathrm{g} / \mathrm{L}$. The coefficient of variation was established in 10 replicates on two separate occasions at each concentration.

\section{Clinical characteristics and outcome}

Clinical characteristics, cardiovascular risk factors, and drugs taken on admission were documented. Hyperlipidaemia and hypertension were defined as either a documented history or the use of a lipid lowering or antihypertensive drug, respectively. Thrombolysis in myocardial infarction (TIMI) risk scores were calculated and the presence of any electrocardiographic changes were recorded. Management during the index admission was assessed, including referral to specialist cardiology services, coronary angiography, coronary revascularisation, and use of medical treatments.

Subsequent readmission with myocardial infarction or death from any cause was recorded. Myocardial infarction was defined according to international guidelines where there was evidence of myocardial necrosis by using plasma troponin concentration of $\geq 0.050 \mu \mathrm{g} / \mathrm{L}$ as the diagnostic threshold in a clinical setting consistent with myocardial ischemia. ${ }^{1}$

\section{Statistical analysis}

We compared continuous variables with analysis of variance and categorical variables with $\chi^{2}$ test or exact methods where the expected values were small across groups. Event-free survival (reinfarction and death) was compared with Kaplan-Maier survival curves and log rank tests.

We used logistic regression adjusted for potential confounders to model the association between troponin concentration and event-free survival at 12 months. Missing data were uncommon for variables included in the regression model (0-7.5\% missing data) and therefore complete case analysis was performed with 95 patients excluded from the analysis because of missing data for covariates. In sensitivity analyses, we analysed time to death or recurrent myocardial infarction in Cox proportional hazards models. We examined the linearity of the association between troponin concentration and odds of death or recurrent myocardial infarction using generalised additive models. Data were analysed with SAS version 9 (SAS Institute, Cary, NC, US), GraphPad Prism (GraphPad, La Jolla, CA, US), and R 211.1 (Vienna, Austria).

\section{Results}

We identified 3434 patients who met the inclusion criteria, of whom 1342 had one or more of the prespecified exclusion criteria, resulting in a final study population of 2092 patients with suspected acute coronary syndrome. Within this population, troponin concentrations were $<0.012 \mu \mathrm{g} / \mathrm{L}$ in $988(47 \%)$, $0.012-0.049 \mu \mathrm{g} / \mathrm{L}$ in $352(17 \%)$, and $\geq 0.050 \mu \mathrm{g} / \mathrm{L}$ in $752(36 \%)$ patients.

Adoption of the 99th centile as the diagnostic threshold would increase the number of patients with a diagnosis of myocardial infarction from $36 \%$ (752/2092) to 53\% (1104/2092), a relative increase of $47 \%$. 


\section{Clinical characteristics}

Patients with troponin concentrations $0.012-0.049 \mu \mathrm{g} / \mathrm{L}$ were older and more likely to have a history of ischaemic heart disease, previous revascularisation, stroke, hypertension, and hyperlipidaemia than those who had concentrations $<0.012 \mu \mathrm{g} / \mathrm{L}$ (table $1 \Downarrow$ ). They were also more likely to have an abnormal result on 12 lead electrocardiography (ST segment depression, $\mathrm{T}$ wave inversion, or bundle branch block) and renal impairment and to already be established on cardiac drugs than patients with troponin concentrations $<0.012 \mu \mathrm{g} / \mathrm{L}$.

Patients with troponin concentrations $0.012-0.049 \mu \mathrm{g} / \mathrm{L}$ were a similar age to the patients with troponin concentrations $\geq 0.050$ $\mu \mathrm{g} / \mathrm{L}$, although they were more likely to have a history of ischaemic heart disease and coronary revascularisation and to be established on cardiac drugs before admission $(\mathrm{P}<0.05$ for all). There were no differences in renal function between these groups of patients, but those with concentrations 0.012-0.049 $\mu \mathrm{g} / \mathrm{L}$ were more likely to present with $\mathrm{T}$ wave inversion or bundle branch block on the 12 lead electrocardiogram and less likely to have ST segment depression or elevation.

\section{Management during index admission}

Rates of referral to cardiology and for coronary revascularisation did not differ between patients with troponin concentrations $<0.012 \mu \mathrm{g} / \mathrm{L}$ and $0.012-0.049 \mu \mathrm{g} / \mathrm{L}$. Compared with those with troponin concentrations $\geq 0.050 \mu \mathrm{g} / \mathrm{L}$, patients with troponin concentrations of $0.012-0.049 \mu \mathrm{g} / \mathrm{L}$ were less likely to be diagnosed with unstable angina or an acute coronary syndrome $(98 / 352(28 \%) v 692 / 752(92 \%))$, referred to a cardiologist $(129 / 352(37 \%) v 642 / 752(85 \%))$, receive dual antiplatelet treatment $(46 / 352(13 \%) v 550 / 752(73 \%))$, or undergo coronary revascularisation $(16 / 352(5 \%) v 394 / 752(52 \%))(\mathrm{P}<0.001$ for all) (table $2 \Downarrow$ ).

\section{Clinical outcomes}

Patients were followed up for a median of 446 (range 366-572) days. At 12 months, patients with troponin concentrations of $0.012-0.049 \mu \mathrm{g} / \mathrm{L}$ were four times more likely to have died or been readmitted with recurrent myocardial infarction than those with troponin concentrations $<0.012 \mu \mathrm{g} / \mathrm{L}(47 / 352(13 \%) v$ $31 / 988(3 \%), \mathrm{P}<0.001$, odds ratio $4.7,95 \%$ confidence interval 2.9 to 7.9 ; table $3 \Downarrow$ and fig $1 \Downarrow$ ). Differences in outcome were already apparent at three months, with 19/352 (5\%) patients with troponin concentration $0.012-0.049 \mu \mathrm{g} / \mathrm{L}$ dead or readmitted with a myocardial infarction compared with $13 / 988(1 \%)$ of patients with troponin concentration $<0.012 \mu \mathrm{g} / \mathrm{L}(\mathrm{P}<0.001$, odds ratio $4.6,2.5$ to 8.5 ).

After adjustment for age, sex, history of vascular disease, diabetes mellitus, hypertension, and hyperlipidaemia, troponin concentration $0.012-0.049 \mu \mathrm{g} / \mathrm{L}$ predicted death or recurrent myocardial infarction at 12 months with an adjusted odds ratio of 2.5 (1.5 to 4.3 ) compared with those with troponin

concentrations $<0.012 \mu \mathrm{g} / \mathrm{L}(\mathrm{P}<0.001)$. Similar estimates were obtained in sensitivity analyses with additional adjustment for smoking status, estimated glomerular filtration rate, and abnormal results on echocardiography (2.3, 1.3 to 4.1). Hazard ratios for time to first event obtained in Cox proportional hazards models were similar to the odds ratios for death or recurrent myocardial infarction at one year.

The association between troponin and risk of death or recurrent myocardial infarction was non-linear $(\mathrm{P}=0.005$, fig $2 \Downarrow)$, but there was no evidence of a threshold at the $10 \%$ coefficient of variation $(0.050 \mu \mathrm{g} / \mathrm{L})$ or the 99 th centile $(0.012 \mu \mathrm{g} / \mathrm{L})$. Instead, risk increased from an undetectable level to concentrations of about $0.020 \mu \mathrm{g} / \mathrm{L}$, at which point a threshold was observed above which risk of death or recurrent myocardial infarction did not increase further. An increase in the proportion of patients dead or readmitted with myocardial infarction at one year was observed with each quarter between $0.012 \mu \mathrm{g} / \mathrm{L}$ and $0.050 \mu \mathrm{g} / \mathrm{L}$ (fig $3 \Downarrow$ ). Clinical outcomes in the lowest quarter (0.012-0.014 $\mu \mathrm{g} / \mathrm{L}$ ) were similar to those in patients with troponin concentrations $<0.012 \mu \mathrm{g} / \mathrm{L}$, and outcomes in the highest quarter (0.026-0.049 $\mu \mathrm{g} / \mathrm{L})$ were similar to those patients with troponin concentrations $\geq 0.050 \mu \mathrm{g} / \mathrm{L}$. The coefficient of variation for troponin measured within each quarter increased from $7.2 \%$ at the diagnostic threshold of $0.050 \mu \mathrm{g} / \mathrm{L}$, to $20.8 \%$ at the 99 th centile of $0.012 \mu \mathrm{g} / \mathrm{L}$, to $28.9 \%$ at concentrations below the 99 th centile (fig $3 \Downarrow$ ).

Despite reductions in the precision of the assay at low concentrations, plasma troponin concentration remained a good discriminator for death and recurrent myocardial infarction with a $\mathrm{C}$ statistic (area under the curve) of 0.75 for patients with troponin concentrations $<0.050 \mu \mathrm{g} / \mathrm{L}$. Lowering the diagnostic threshold from $0.050 \mu \mathrm{g} / \mathrm{L}$ to $0.012 \mu \mathrm{g} / \mathrm{L}$ increased the negative predictive value of troponin from $94 \%$ to $97 \%$, while the positive predictive value decreased from $25 \%$ to $22 \%$ (see appendix table on bmj.com).

\section{Discussion}

In patients with suspected acute coronary syndrome, any increase in plasma troponin concentration above the 99th centile of a healthy reference population was associated with recurrent myocardial infarction or death. Lowering the diagnostic threshold to the 99th centile and accepting greater assay imprecision will identify more patients at risk of recurrent events but would potentially increase the diagnosis of myocardial infarction by $47 \%$.

\section{Risk stratification}

Patients with suspected acute coronary syndrome and increased troponin concentrations measured with conventional assays are known to have poorer short and long term clinical outcomes. ${ }^{7-10}$ These observations were derived from a homogenous group of high risk selected patients participating in clinical trials. The definition of a raised troponin concentration differed widely between these studies, and the prognosis of unselected patients with small increases in troponin concentration detectable only with contemporary sensitive troponin assays has not been assessed and remains uncertain. ${ }^{11}$

We have shown that unselected patients with suspected acute coronary syndrome and small increases in troponin concentration above the 99 th centile $(0.012 \mu \mathrm{g} / \mathrm{L})$, but below our diagnostic threshold based on the $10 \%$ coefficient of variation $(0.050 \mu \mathrm{g} / \mathrm{L})$, were four to five times more likely to die or have a recurrent myocardial infarct than those with plasma troponin concentrations below the 99th centile. Although patients with troponin concentration $0.012-0.049 \mu \mathrm{g} / \mathrm{L}$ were older and more likely to have established ischaemic heart disease or cardiovascular risk factors than those patients with a troponin concentration in the normal reference range, plasma troponin concentration remained an independent predictor of clinical outcome even after adjustment for these clinical characteristics. Our findings are consistent with recent studies of patients with acute coronary syndrome participating in randomised clinical trials where troponin concentrations above the 99th centile were associated with poorer outcomes. ${ }^{12}{ }^{13}$ Importantly, our study population comprised consecutive unselected "real world" patients admitted with suspected cardiac chest pain rather than 
a homogeneous group of patients with a clinical diagnosis of acute coronary syndrome who were receiving optimal treatment. We currently do not report troponin concentrations below the diagnostic threshold $(0.050 \mu \mathrm{g} / \mathrm{L})$ for myocardial infarction and therefore we have yet to realise the full potential for sensitive troponin assays to improve risk stratification in clinical practice. Lowering the diagnostic threshold further will identify many more patients who will go on to have recurrent events. It has recently been shown that the GRACE score continues to be a powerful predictor of clinical outcome even with the availability of high sensitive cardiac troponin assays. ${ }^{14}$ Troponin, however, is included as a categorical rather than a continuous variable in the GRACE score, and therefore the true potential for sensitive troponin assays to add to current clinical risk prediction tools requires further evaluation.

\section{Diagnosis of myocardial infarction}

Will lowering the diagnostic threshold and reclassification of patients with suspected acute coronary syndrome as myocardial infarction alter clinical outcomes? We have previously shown that lowering the diagnostic threshold from $0.200 \mu \mathrm{g} / \mathrm{L}$ to 0.050 $\mu \mathrm{g} / \mathrm{L}$ was associated with a change in clinical practice, with more referrals to cardiac specialists, more coronary angiography, and wider use of evidenced based treatments. ${ }^{2}$ This alteration in diagnosis and practice was associated with a marked improvement in clinical outcome with a halving in the rates of recurrent myocardial infarction and death. In our current study, patients with troponin concentrations $0.012-0.049 \mu \mathrm{g} / \mathrm{L}$ did not receive a diagnosis of or were managed for myocardial infarction, and were less likely to be referred to a cardiologist, or considered for revascularisation, despite the higher rates of previous ischaemic heart disease. It remains to be established whether diagnosis and treatment in these patients with acute myocardial infarction would also improve clinical outcomes to a similar extent.

While sensitive troponin assays undoubtedly improve our ability to rule out acute myocardial infarction, ${ }^{15}{ }^{16}$ many clinicians are concerned that the use of progressively lower diagnostic thresholds will result in the misdiagnosis of myocardial infarction and that small increases in troponin concentrations could be caused by other conditions. This could lead to inappropriate hospital admissions, misdiagnosis, initiation of potentially detrimental treatments, and poorer clinical outcomes for patients. In our study, adoption of the 99th centile as the diagnostic threshold would potentially result in a $47 \%$ increase in the number of patients with a diagnosis of myocardial infarction and would have major implications for healthcare resources, public health targets, and government statistics and on the employment prospects and insurance policies of our patients. If a similar increase in the rate of diagnosis were to occur across the UK, we anticipate the number of patients with acute myocardial infarction would increase by about 42000 a year. ${ }^{17}{ }^{18}$ Lowering the diagnostic threshold would also potentially increase the number of patients referred for inpatient coronary angiography by $42 \%$ and increase the use of secondary prevention by $8 \%$ for statins, $12 \%$ for angiotensin converting enzyme inhibitors, and $30 \%$ for clopidogrel. Moreover, the impact of adopting the 99th centile on healthcare resources is likely to be underestimated here as we included only patients with suspected acute coronary syndrome. We identified several prespecified exclusion criteria to avoid patients with clearly defined non-cardiac or non-coronary causes of chest pain and therefore our analysis does not take into account patients with secondary causes of myocardial ischemia who are likely to undergo additional investigation.
In our previous study patients with an undisclosed troponin of $0.05-0.19 \mu \mathrm{g} / \mathrm{L}$ had a high event rate of $39 \%$ at one year. In comparison, patients with undisclosed troponin concentrations of $0.012-0.049 \mu \mathrm{g} / \mathrm{L}$ were at lower risk, with a one year event rate of $13 \%$. Therefore there might be less to gain from the reclassification and treatment of these patients for myocardial infarction. As such we believe it is important to assess whether this change in practice will translate into improvements in clinical outcomes. This requires additional prospective studies across a range of healthcare settings with a formal assessment of cost effectiveness.

\section{Defining an appropriate diagnostic threshold}

The successful design of prospective clinical trials will critically depend on the selection and determination of the population of apparently healthy people with which to define the normal reference range. ${ }^{19}$ Troponin concentrations in apparently healthy people differ between men and women, ${ }^{20}$ increase with age, ${ }^{21}$ and are even raised in endurance athletes, ${ }^{22}$ yet current guidance recommends a single diagnostic threshold. Furthermore, in a large cohort of patients with stable coronary heart disease and preserved left ventricular function, plasma troponin concentrations were above the 99th centile in $11 \%$ of patients. ${ }^{23}$ When we started this study, the manufacturers of the ARCHITECT STAT troponin I assay defined the 99th centile as $0.012 \mu \mathrm{g} / \mathrm{L}$ but, after additional studies in apparently healthy populations, the 99 th centile was revised to $0.028 \mu \mathrm{g} / \mathrm{L}$. The appropriate population from which to determine the reference range for patients with suspected acute coronary syndrome has yet to be determined and perhaps should include patients with stable coronary artery disease.

When examining the linearity of association between troponin concentration and death or recurrent myocardial infarction, we found no evidence of a threshold at the $10 \%$ coefficient of variation or the 99th centile. This is perhaps not surprising given these levels are based on the limits of assay precision or assumptions about the normal distribution of troponin in an unrelated population, respectively. In our population of patients with suspected acute coronary syndrome, the risk of recurrent events increased linearly from an undetectable level with a genuflection and plateau at a troponin concentration of about $0.020 \mu \mathrm{g} / \mathrm{L}$, above which risk does not seem to increase further. It is tempting to speculate that this concentration could represent a more clinically relevant threshold on which to base the diagnosis of myocardial infarction.

Our data support the need to re-evaluate the level of precision recommended for the current generation of troponin assays. While prototype high sensitive troponin I assays ${ }^{24} 25$ and a commercially available high sensitive troponin $\mathrm{T}$ assay ${ }^{22}$ can show less than $10 \%$ coefficient of variation at the 99th centile, most do not. ${ }^{26}$ The Biochemistry Group of the Global Task Force recently recommended the use of lower diagnostic thresholds, even though the coefficient of variation might be as high as $20 \%$ at the 99 th centile. $^{5}$ This change in position was based partly on modelling exercises that suggest assays with greater imprecision of up to $20 \%$ coefficient of variation do not affect diagnostic accuracy. ${ }^{6}$ Our findings support these

recommendations; using higher diagnostic thresholds to maximise assay precision will miss a considerable proportion of patients with suspected acute coronary syndrome at risk of recurrent events. 


\section{Generalisability}

Lowering the diagnostic threshold for myocardial infarction will have major implications for both specialists and general physicians working in emergency departments or acute receiving units in secondary and tertiary care hospitals. While we report findings from a single tertiary care hospital using a specific contemporary sensitive troponin I assay and diagnostic threshold, this issue is not particular to our centre or indeed the assay. Our study population represents unselected patients who self present or are referred from primary care practitioners to our institution. While the troponin concentration at the 99th centile will differ slightly between assays, the impact of adopting the 99th centile on the rate of diagnosis of myocardial infarction will be similar across all assays. Troponin I assays are used in the diagnosis of myocardial infarction in more than $70 \%$ of clinical laboratories worldwide, with the ARCHITECT STAT troponin I assay being used in more than 50 acute hospitals in the UK alone. One of the main strengths of our study is that we included all consecutive patients self presenting or referred by their general practitioner to the emergency department, in contrast to many clinical studies evaluating sensitive troponin assays that recruit a highly selected group of patients participating in international multicentre randomised controlled trials. We therefore believe that our findings have implications for many disciplines in clinical practice and are more generalisable to the broad group of patients presenting with suspected cardiac chest pain to most acute secondary and tertiary care centres.

\section{Limitations}

Our study has some potential limitations. Firstly, these observations are derived from a retrospective analysis from a single tertiary cardiac centre and need to be replicated in prospective studies including patients assessed in different healthcare settings. Secondly, as patients with troponin concentrations $0.012-0.049 \mu \mathrm{g} / \mathrm{L}$ were considered to have a "normal" troponin concentration by the clinician responsible for their care, the troponin test was not repeated in most patients. We are therefore unable to determine whether raised troponin concentration in these complex patients with previous ischaemic heart disease was caused by dynamic release of troponin in the context of plaque rupture, myocardial ischaemia, and infarction, or whether it reflects cardiomyocyte apoptosis in patients with ischaemic cardiomyopathy. ${ }^{27}$ Thirdly, while we excluded patients with clear non-cardiac causes of chest pain and renal function was similar in patients with troponin concentrations 0.012-0.049 $\mu \mathrm{g} / \mathrm{L}$ and $\geq 0.050 \mu \mathrm{g} / \mathrm{L}$, it remains possible that myocardial ischaemia in some patients will be secondary to non-cardiac illness. The true impact of lowering the diagnostic threshold to the 99th centile on the incidence of myocardial infarction and on clinical outcomes will be determined only through a prospective controlled trial.

\section{Conclusions}

In patients with suspected acute coronary syndrome, any increase in troponin concentration above the 99th centile predicts recurrent myocardial infarction and death. Accepting greater assay imprecision to permit lowering the diagnostic threshold will identify patients at high risk of recurrent events. Prospective trials are necessary to establish whether treatment for myocardial infarction in these patients will reduce risk and improve clinical outcomes.
Contribution: NLM, SW, MAD, KAAF, and DEN conceived and designed the study. KKL, AMDC, MM, and MS acquired the data. KKL, NLM, and DAM analysed and interpreted the data. NLM and DEN drafted the initial manuscript. KKL, DAM, AMDC, MM, MS, SW, MAD, KAAF, and DEN made critical revisions of the manuscript for important intellectual content. MAD, KAAF, and DEN contributed equally to this work. All authors approved the final version. NLM is guarantor.

Funding: This research received no specific grant from any funding agency in the public, commercial, or not-for-profit sectors. NLM is supported by an intermediate clinical research fellowship from the British Heart Foundation (BHF) (FS/10/024/28266). KAAF and DEN are supported by BHF Chair Awards (CH/92010/6773 and CH/09/002/26360, respectively).

Competing interests: All authors have completed the ICMJE uniform disclosure form at www.icmje.org/coi_disclosure.pdf (available on request from the corresponding author) and declare: no support from any organisation for the submitted work; NLM and SW have specified relationships with Abbott Diagnostics that might have an interest in the submitted work in the previous three years.

Ethical approval: Not required. The study protocol was reviewed by the Chairman and Scientific Advisor of the Lothian research ethics committee, who advised that the proposed study represented clinical audit and service evaluation and therefore did not require approval. Data collection and record linkage were performed with permission from the Caldicott Guardian.

Data sharing: No additional data available.

Thygesen K, Alpert JS, White HD, Jaffe AS, Apple FS, Galvani M, et al. Universal definition of myocardial infarction. Circulation 2007;116:2634-53.

2 Bauer A, Gawaz M. Sensitive cardiac troponin assays. N Engl J Med 2009;361:2575-7.

3 Morrow DA, Cannon CP, Jesse RL, Newby LK, Ravkilde J, Storrow AB, et al. National Academy of Clinical Biochemistry Laboratory Medicine Practice Guidelines: clinical characteristics and utilization of biochemical markers in acute coronary syndromes. Clin Chem 2007;53:552-74.

4 Mills NL, Churchhouse AM, Lee KK, Anand A, Gamble D, Shah AS, et al. Implementation of a sensitive troponin I assay and risk of recurrent myocardial infarction and death in patients with suspected acute coronary syndrome. JAMA 2011;305:1210-6.

5 Jaffe AS, Apple FS, Morrow DA, Lindahl B, Katus HA. Being rational about (im)precision: a statement from the Biochemistry Subcommittee of the Joint European Society of Cardiology/American College of Cardiology Foundation/American Heart Association/World Heart Federation Task Force for the definition of myocardial infarction. Clin Chem 2010;56:941-3.

6 Kupchak P, Wu AH, Ghani F, Newby LK, Ohman EM, Christenson RH. Influence of imprecision on ROC curve analysis for cardiac markers. Clin Chem 2006;52:752-3.

7 Antman EM, Tanasijevic MJ, Thompson B, Schactman M, McCabe CH, Cannon CP, et al. Cardiac-specific troponin I levels to predict the risk of mortality in patients with acute coronary syndromes. N Engl J Med 1996:335;1342-9.

8 Lindahl B, Venge P, Wallentin L, the FRISC Study Group. Relation between troponin T and the risk of subsequent cardiac events in unstable coronary artery disease. Circulation 1996:93;1651-7.

9 Lindahl B, Toss H, Siegbahn A, Venge P, Wallentin L. Markers of myocardial damage and inflammation in relation to long-term mortality in unstable coronary artery disease. $N$ Engl J Med 2000:343;1139-47.

10 Morrow DA, Cannon CP, Rifai N, Frey MJ, Vicari R, Lakkis N, et al. Ability of minor elevations of troponins $I$ and $T$ to predict benefit from an early invasive strategy in patients with unstable angina and non-ST elevation myocardial infarction. JAMA 2001:286;2405-12.

11 Morrow DA. Clinical application of sensitive troponin assays. N Engl J Med. 2009;361:913-5.

12 Bonaca M, Scirica B, Sabatine M, Dalby A, Spinar J, Murphy SA, et al. Prospective evaluation of the prognostic implications of improved assay performance with a sensitive assay for cardiac troponin I. J Am Coll Cardiol 2010;55:2118-24.

13 Lindahl $B$, Venge $P$, James $S$. The new high-sensitivity cardiac troponin $T$ assay improves risk assessment in acute coronary syndromes. Am Heart J 2010;160:224-9.

14 Meune C, Drexler B, Haaf P, Reichlin T, Reiter M, Meissner J, et al. The GRACE score's performance in predicting in-hospital and 1-year outcome in the era of high-sensitivity cardiac troponin assays and B-type natriuretic peptide. Heart 2011;97:1479-83.

15 Body R, Carley S, McDowell G, Jaffe AS, France M, Cruickshank K, et al. Rapid exclusion of acute myocardial infarction in patients with undetectable troponin using a high-sensitivity assay. J Am Coll Cardiol 2011;58:1332-9

16 Collinson P, Goodacre S, Gaze D, Gray A. Very early diagnosis of chest pain by point-of-care testing: comparison of the diagnostic efficiency of a panel of cardiac biomarkers compared with troponin measurement alone in the RATPAC trial. Heart 2012:98;312-8.

17 NHS National Services Scotland: Information Services Division (ISD). Hospital activity in coronary heart disease. National Statistics Publication for Scotland, 2011;xx:1-20.

18 Myocardial Ischaemia National Audit Project (MINAP). How the NHS cares for patients with heart attack. 10th public report. National Institute for Cardiovascular Research, 2011;xx:1-84.

19 Eggers KM, Jaffe AS, Lind L, Venge P, Lindahl B. Value of cardiac troponin I cutoff concentrations below the 99th percentile for clinical decision-making. Clin Chem 2009;55:85-92. 


\section{What is already known on this topic}

The universal definition of myocardial infarction recommends the 99th centile as the diagnostic threshold for troponin concentration in patients with acute coronary syndrome

Most institutions use a diagnostic threshold above the 99th centile because of limitations in assay precision and concern about false positive results and inappropriate diagnosis of myocardial infarction

\section{What this study adds}

Any increase in troponin concentration above the 99th centile predicts recurrent myocardial infarction and death in patients with suspected acute coronary syndrome

Accepting greater assay imprecision to permit lowering the diagnostic threshold will identify patients at high risk of recurrent events but will increase the diagnosis of myocardial infarction by $47 \%$

Prospective trials are necessary to establish whether treatment for myocardial infarction in these patients will reduce risk and improve clinical outcomes

20 Apple FS, Simpson PA, Murakami MM. Defining the serum 99th percentile in a normal reference population measured by a high-sensitivity cardiac troponin I assay. Clin Biochem 2010;43:1034-6.

21 Koerbin G, Tate JR, Hickman PE. Analytical characteristics of the Roche highly sensitive troponin T assay and its application to a cardio-healthy population. Ann Clin Biochem 2010;47:524-8.

22 Mingels A, Jacobs L, Michielsen E, Swaanenburg J, Wodzig W, van Dieijen-Visser M. Reference population and marathon runner sera assessed by highly sensitive cardiac troponin T and commercial cardiac troponin T and I assays. Clin Chem 2009:55:101-8.

23 Omland T, de Lemos JA, Sabatine MS, Christophi CA, Rice MM, Jablonski KA, et al. A sensitive cardiac troponin T assay in stable coronary artery disease. $N$ Engl $\mathrm{J} \mathrm{Med}$ 2009:361:2538-47.

24 Venge P, Johnston N, Lindahl B, James S. Normal plasma levels of cardiac troponin I measured by the high-sensitivity cardiac troponin I access prototype assay and the impact on the diagnosis of myocardial ischemia. J Am Coll Cardiol 2009;54:1165-72.

25 Sabatine MS, Morrow DA, de Lemos JA, Jarolim P, Braunwald E. Detection of acute changes in circulating troponin in the setting of transient stress test-induced myocardial ischaemia using an ultrasensitive assay: results from TIMI 35. Eur Heart J 2009;30:162-9.
26 Apple FS. A new season for cardiac troponin assays: it's time to keep a scorecard. Clin Chem 2009;55:1303-6.

27 Eggers KM, Lind L, Ahlstrom H, Bjerner T, Ebeling Barbier C, Larsson A, et al. Prevalence and pathophysiological mechanisms of elevated cardiac troponin I levels in a population-based sample of elderly subjects. Eur Heart J 2008;29:2252-8.

\section{Accepted: 19 January 2012}

\section{Cite this as: BMJ 2012;344:e1533}

This is an open-access article distributed under the terms of the Creative Commons Attribution Non-commercial License, which permits use, distribution, and reproduction in any medium, provided the original work is properly cited, the use is non commercial and is otherwise in compliance with the license. See: http://creativecommons.org/licenses/by$\mathrm{nc} / 2.0 /$ and http://creativecommons.org/licenses/by-nc/2.0/legalcode. 


\section{Tables}

Table 1| Baseline characteristics of all patients with suspected acute coronary syndrome stratified by peak troponin concentration. Figures are numbers (percentage) of patients unless stated otherwise

\begin{tabular}{|c|c|c|c|c|c|c|c|c|}
\hline & \multicolumn{4}{|c|}{ Peak troponin concentration $(\mu \mathrm{g} / \mathrm{L})$} & \multirow[b]{2}{*}{ P value* } & \multicolumn{3}{|c|}{ Post hoc analysis $P$ values } \\
\hline & All $(n=2092)$ & $<0.012(n=988)$ & $\begin{array}{c}0.012-0.049 \\
(n=352)\end{array}$ & $\geq 0.050(n=752)$ & & $\begin{array}{c}<0.012 v \\
0.012-0.049\end{array}$ & $\begin{array}{l}<0.012 v \\
\geq 0.050\end{array}$ & $\begin{array}{c}0.012-0.049 \mathrm{v} \\
\geq 0.050\end{array}$ \\
\hline $\begin{array}{l}\text { Mean (SD) age } \\
\text { (years) }\end{array}$ & $65(15)$ & $60(14)$ & $70(14)$ & $68(14)$ & $<0.001$ & $<0.001$ & $<0.001$ & $>0.05$ \\
\hline Men & $1192(57)$ & $524(53)$ & $207(59)$ & $461(61)$ & 0.002 & 0.071 & $<0.001$ & 0.429 \\
\hline \multicolumn{9}{|l|}{ Medical history: } \\
\hline Previous IHD & $1161(55)$ & $499(51)$ & $264(75)$ & $398(55)$ & $<0.001$ & $<0.001$ & 0.333 & $<0.001$ \\
\hline $\begin{array}{l}\text { Previous } \\
\text { revascularisation }\end{array}$ & $460(22)$ & $202(20)$ & $100(28)$ & $158(19)$ & 0.006 & 0.003 & 0.811 & 0.008 \\
\hline Previous stroke & $160(8)$ & $59(6)$ & $35(10)$ & $66(9)$ & 0.019 & 0.015 & 0.031 & 0.576 \\
\hline $\begin{array}{l}\text { Peripheral vascular } \\
\text { disease }\end{array}$ & $117(6)$ & $46(5)$ & $17(5)$ & $54(7)$ & 0.060 & - & - & - \\
\hline \multicolumn{9}{|l|}{ Risk factors: } \\
\hline Current smoker & $611(29)$ & $299(30)$ & $67(19)$ & $245(33)$ & $<0.001$ & $<0.001$ & 0.321 & $<0.001$ \\
\hline Ex-smoker & $430(21)$ & $195(20)$ & $91(26)$ & $145(19)$ & 0.028 & 0.019 & 0.855 & 0.015 \\
\hline Non-smoker & $1051(50)$ & $494(50)$ & $194(55)$ & $362(48)$ & 0.096 & - & - & - \\
\hline Hypertension & $791(38)$ & $326(33)$ & $157(45)$ & $308(42)$ & $<0.001$ & $<0.001$ & $<0.001$ & 0.267 \\
\hline Hyperlipidaemia & $1020(49)$ & $445(45)$ & $218(62)$ & $357(47)$ & $<0.001$ & $<0.001$ & 0.332 & $<0.001$ \\
\hline Family history & $405(19)$ & $224(23)$ & $39(11)$ & $142(19)$ & $<0.001$ & $<0.001$ & 0.058 & $<0.001$ \\
\hline Diabetes mellitus & $346(17)$ & $137(14)$ & $63(18)$ & $146(19)$ & 0.006 & 0.081 & 0.002 & 0.565 \\
\hline \multicolumn{9}{|c|}{ Mean (SD) values on biochemistry: } \\
\hline Haemoglobin $(\mathrm{g} / \mathrm{L})$ & $134(18)$ & $137(17)$ & $130(17)$ & $134(20)$ & $<0.001$ & $<0.001$ & $<0.01$ & $<0.01$ \\
\hline Estimated GFR & $75(25)$ & $81(23)$ & $68(26)$ & $69(26)$ & $<0.001$ & $<0.001$ & $<0.001$ & $>0.05$ \\
\hline Cholesterol (mmol/L) & $4.8(1.3)$ & $4.9(1.2)$ & $4.5(1.5)$ & $4.8(1.3)$ & $<0.001$ & $<0.001$ & $>0.05$ & $<0.01$ \\
\hline \multicolumn{9}{|c|}{ Electrocardiographic changes: } \\
\hline ST depression & $296(14)$ & $70(8)$ & $49(14)$ & $177(24)$ & $<0.001$ & $<0.001$ & $<0.001$ & $<0.001$ \\
\hline ST elevation & $244(12)$ & $10(1)$ & $3(1)$ & $231(31)$ & $<0.001$ & 1.000 & $<0.001$ & $<0.001$ \\
\hline T wave inversion & $305(15)$ & $136(14)$ & $70(20)$ & $99(15)$ & 0.008 & 0.008 & 0.724 & 0.005 \\
\hline Bundle branch block & $219(10)$ & $63(6)$ & $67(19)$ & $89(12)$ & $<0.001$ & $<0.001$ & $<0.001$ & 0.002 \\
\hline $\begin{array}{l}\text { Mean (SD) TIMI risk } \\
\text { score }\end{array}$ & $2.4(1.5)$ & $1.7(1.4)$ & $3.5(1.2)$ & $3.3(1.4)$ & $<0.001$ & $<0.001$ & $<0.001$ & $>0.05$ \\
\hline \multicolumn{9}{|l|}{ Drugs on admission: } \\
\hline Aspirin & $1065(51)$ & $470(48)$ & $213(61)$ & $382(51)$ & $<0.001$ & $<0.001$ & 0.191 & 0.003 \\
\hline Clopidogrel & $242(12)$ & $113(11)$ & $53(15)$ & $76(10)$ & 0.056 & - & - & - \\
\hline B blockers & $682(33)$ & $307(31)$ & $141(40)$ & $234(31)$ & 0.005 & 0.003 & 1.000 & 0.004 \\
\hline ACE inhibitors & 741 (35) & $302(31)$ & $162(46)$ & $277(37)$ & $<0.001$ & $<0.001$ & 0.007 & 0.005 \\
\hline Statins & $1054(50)$ & $469(48)$ & $220(63)$ & $365(49)$ & $<0.001$ & $<0.001$ & 0.663 & $<0.001$ \\
\hline
\end{tabular}

IHD=ischaemic heart disease; GFR=glomerular filtration rate; TIMI=thrombolysis in myocardial infarction; ACE=angiotensin converting enzyme.

*Comparisons between groups of patients performed with analysis of variance for continuous variables with Tukey's multiple comparison test between groups and $\chi^{2}$ test for categorical variables with Bonferroni correction to account for multiple comparisons in post hoc analysis $(P<0.0167$ indicates significance). 
Table 2| Inpatient management of patients with suspected acute coronary syndrome stratified by peak troponin concentration. Figures are numbers (percentages)

\begin{tabular}{|c|c|c|c|c|c|c|c|c|}
\hline & \multicolumn{4}{|c|}{ Peak troponin concentration $(\mu \mathrm{g} / \mathrm{L})$} & \multirow[b]{2}{*}{ P value* } & \multicolumn{3}{|c|}{ Post hoc analysis $P$ value } \\
\hline & All $(n=2092)$ & $<0.012(n=988)$ & $\begin{array}{c}0.012-0.049 \\
(n=352)\end{array}$ & $\geq 0.050(n=752)$ & & $\begin{array}{c}<0.012 v \\
0.012-0.049\end{array}$ & $<0.012 v \geq 0.050$ & $\begin{array}{c}0.012-0.049 v \\
\geq 0.050\end{array}$ \\
\hline Diagnosis of ACS & $985(47)$ & $195(20)$ & $98(28)$ & $692(92)$ & $<0.001$ & 0.002 & $<0.001$ & $<0.001$ \\
\hline $\begin{array}{l}\text { Cardiology } \\
\text { referral }\end{array}$ & $1081(52)$ & $310(31)$ & $129(37)$ & $642(85)$ & $<0.001$ & 0.074 & $<0.001$ & $<0.001$ \\
\hline $\begin{array}{l}\text { Coronary } \\
\text { angiography }\end{array}$ & $559(27)$ & $61(6)$ & $22(6)$ & $476(63)$ & $<0.001$ & 1.000 & $<0.001$ & $<0.001$ \\
\hline $\mathrm{PCl}$ & $399(19)$ & $22(2)$ & $14(4)$ & $363(48)$ & $<0.001$ & 0.086 & $<0.001$ & $<0.001$ \\
\hline CABG & $37(2)$ & $4(0.4)$ & $2(0.7)$ & $31(4)$ & $<0.001$ & 0.656 & $<0.001$ & $<0.001$ \\
\hline \multicolumn{9}{|l|}{ Drugs on discharge: } \\
\hline Aspirin & $1419(68)$ & $520(53)$ & $232(66)$ & $667(89)$ & $<0.001$ & $<0.001$ & $<0.001$ & $<0.001$ \\
\hline Clopidogrel & $796(38)$ & $133(13)$ & $74(21)$ & $589(78)$ & $<0.001$ & 0.001 & $<0.001$ & $<0.001$ \\
\hline $\begin{array}{c}\text { Dual } \\
\text { antiplatelets }\end{array}$ & $684(33)$ & $88(9)$ & $46(13)$ & $550(73)$ & $<0.001$ & 0.030 & $<0.001$ & $<0.001$ \\
\hline B blockers & $941(45)$ & $322(32)$ & $149(42)$ & $470(63)$ & $<0.001$ & 0.001 & $<0.001$ & $<0.001$ \\
\hline ACE inhibitors & $991(47)$ & $298(30)$ & $165(47)$ & $528(70)$ & $<0.001$ & $<0.001$ & $<0.001$ & $<0.001$ \\
\hline Statins & $1380(66)$ & $497(50)$ & $246(70)$ & $637(85)$ & $<0.001$ & $<0.001$ & $<0.001$ & $<0.001$ \\
\hline
\end{tabular}

$\mathrm{ACS}=$ acute coronary syndrome; $\mathrm{PCl}=$ percutaneous coronary intervention; $\mathrm{CABG}=$ coronary artery bypass grafting; $\mathrm{ACE}=$ angiotensin converting enzyme, $\mathrm{IHD}=$ ischaemic heart disease.

*Variables analysed with $\mathrm{X}^{2}$ test with post hoc Fisher's exact testing between individual groups with significance set at $\mathrm{P}<0.0167$ to account for multiple comparisons. 
Table 3/ Clinical outcomes in patients with suspected acute coronary syndrome stratified by peak troponin concentration below diagnostic threshold. Figures are numbers (percentages) of patients*

\begin{tabular}{|c|c|c|c|c|c|}
\hline & \multicolumn{3}{|c|}{ Peak troponin concentration } & \multirow[b]{2}{*}{$P$ value } & \multirow[b]{2}{*}{ Odds ratio $(95 \% \mathrm{Cl})$} \\
\hline & All $(n=1340)$ & $<0.012(n=988)$ & $0.012-0.049(n=352)$ & & \\
\hline \multicolumn{6}{|l|}{3 months } \\
\hline Death & $16(1.2)$ & $5(0.5)$ & $11(3.1)$ & $<0.001$ & 6.4 (2.2 to 18.5$)$ \\
\hline Myocardial infarction & $20(1.5)$ & $8(0.8)$ & $12(3.4)$ & $<0.001$ & 4.3 (1.8 to 10.7$)$ \\
\hline Death/myocardial infarction & $32(2.3)$ & $13(1.3)$ & $19(5.4)$ & $<0.001$ & $4.6(2.5$ to 8.5$)$ \\
\hline \multicolumn{6}{|l|}{12 months } \\
\hline Death & $43(3.2)$ & $17(1.7)$ & $26(7.4)$ & $<0.001$ & 7.4 (3.8 to 14.2$)$ \\
\hline Myocardial infarction & $46(3.4)$ & $17(1.7)$ & $29(8.2)$ & $<0.001$ & $5.2(2.8$ to 9.5$)$ \\
\hline Death/myocardial infarction & $78(5.8)$ & $31(3.1)$ & $47(13.4)$ & $<0.001$ & $4.7(2.9$ to 7.9$) \dagger$ \\
\hline
\end{tabular}

${ }^{*}$ Complete case analysis performed with 95 patients excluded from analysis because of missing data for covariates.

†2.6 (1.5 to 4.4) adjusted for age, sex, history of vascular disease; 2.5 (1.5 to 4.3) additionally adjusted for diabetes mellitus, hypertension, and hyperlipidaemia. 


\section{Figures}

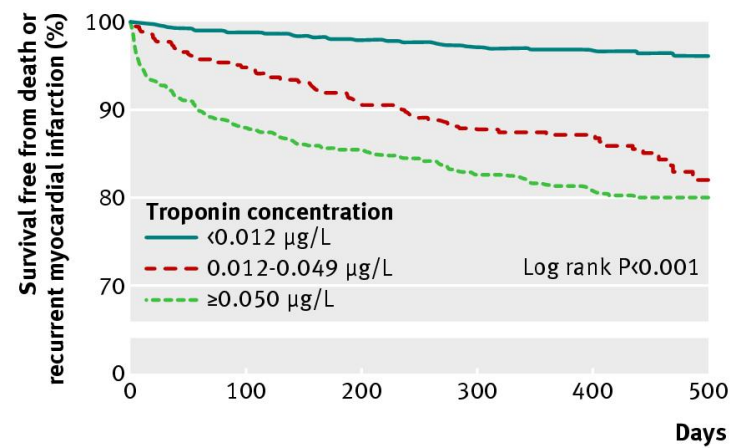

Fig 1 Survival free from death or recurrent myocardial infarction in patients with suspected acute coronary syndrome stratified by plasma troponin concentration

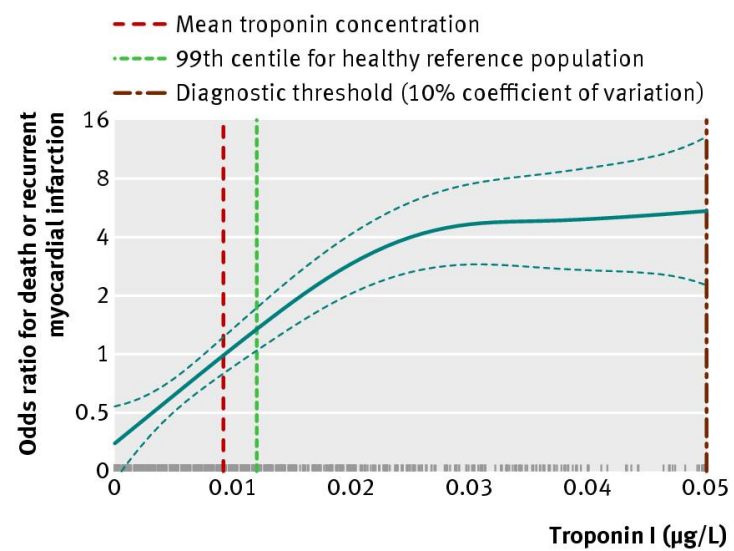

Fig 2 Association between plasma troponin concentration and odds of death or recurrent myocardial infarction. Estimates obtained from generalised additive model with cubic smoothing spline ( $d f=3, P=0.005$ for non-linearity). Rug plot shows density of data for given value of troponin 


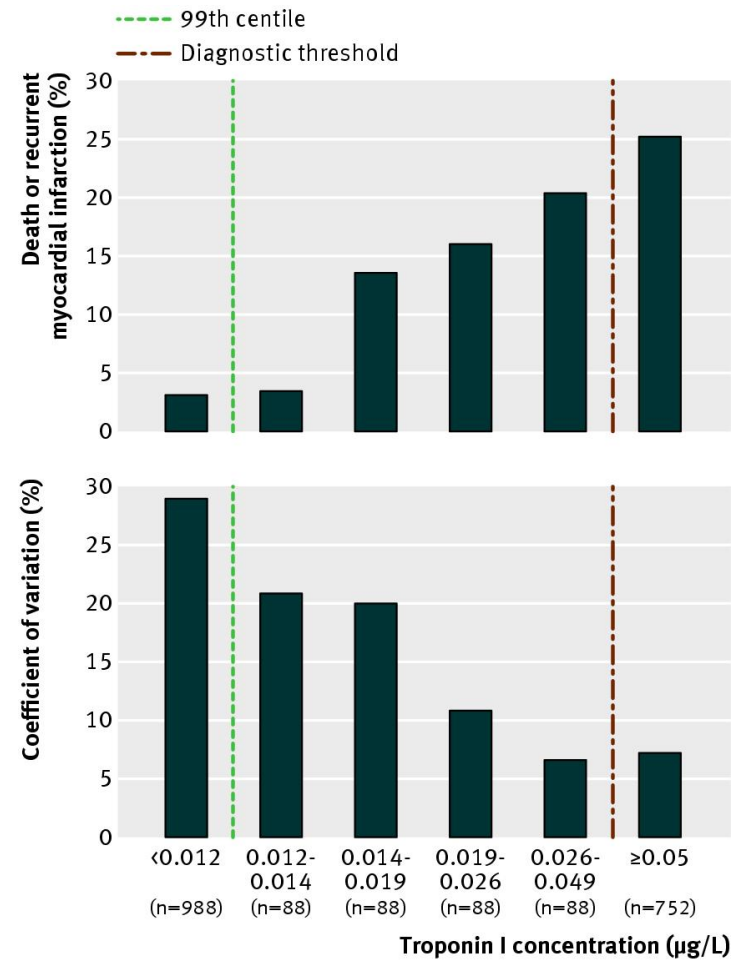

Fig 3 Odds of death or recurrent myocardial infarction in patients stratified by plasma troponin concentration 